Paris Observatory, a post to which he was appointed on the death of Felix Tisserand. Born in Vienna in 1833 of Jewish parents, Loewy passed through the Polytechnic School and University of Vienna and then entered the old Imperial Observatory of the capital, where he was trained by Karl Littrow. Being invited to France by Le Verrier, he became a naturalised Frenchman and in 1864 joined the staff of the Paris Observatory, serving under Le Verrier, Delaunay, Mouchez and Tisserand. He took an active part in the completion of the great Paris Catalogue of Stars and in the inauguration of the International Star Chart. So early as 1871 he proposed to Delaunay the new form of telescope since known as the equatorial coudé, but it was not until 1882 that the first instrument of this kind was erected, the cost of the telescope then being defrayed by the generous banker Raphael Bischoffsheim (1823-1906), the founder of the Nice Observatory. A description of the instrument appeared in NATURE of November 8,1883 , p. 36. For thirty years Loewy was director of the Connaissance des Temps, and from 1872 was a member of the Bureau des Longitudes, taking part with Mouchez in the inauguration of the observatory in the Parc de Montsouris for the instruction of navigators and explorers. From 1873 onwards he was also a member of the Academy of Sciences. He received many honours from learned societies and in 1889 was awarded the gold medal of the Royal Astronomical Society. He died suddenly on October 15, 1907, at the age of seventy-four years, when addressing a meeting of the Conseil des Observatoires astronomiques.

\section{Priestley Bicentenary Celebrations at Warrington}

WHEN non-conformists were debarred from studying at $\mathrm{Oxford}$ and Cambridge, a number of dissenting colleges came into existence, among the most famous and successful of which was the Warrington Academy, through which, during its existence from 1757 until 1783, some four hundred pupils passed. It was in this Academy that Priestley taught from 1762 until 1767, and it was there he wrote his "History of Electricity". In 1898 the Warrington Society was formed with the object of preserving the building which originally housed the Academy, and to-day it possesses an interesting collection of Priestley pictures, books and medallions. In conjunction with the Warrington Philomathic Society, therefore, it held a Priestley commemoration meeting in The Old Academy on March 17, when the Priestley relics were shown to visitors and two addresses were given, the first being by Mr. J. Hawthorn on "Joseph Priestley and Warrington" and the second by J. S. Brome on "Priestley's Scientific Work in Warrington". When Priestley was offered a post at the Academy, he followed Dr. Taylor as tutor in languages although, as he himself wrote, "I should have preferred the office of teaching the mathematics and natural philosophy, for which, I had at that time a great predilection". In spite, however, of being employed five hours a day in lecturing on English, Latin, Hebrew and other subjects, ho yet found time to make experiments and carry on a corre- spondence with Franklin, and it was his scientific work at Warrington which led to his being admitted to the fellowship of the Royal Society.

\section{Stereochemistry and Physics}

THE Faraday lecture of the Chemical Society was delivered at the Royal Institution on March 29 by Prof. Peter Debye, of the University of Leipzig. $\mathrm{He}$ took as his subject "The Relations between Stereochemistry and Physics" and gave a brilliant exposition of certain methods used for the elucidation of molecular shape and dimensions, methods to which his own contributions, both in theory and in experimental technique, have been all-important. Until comparatively recently, the two factors which essentially determine the dielectric constant of a substance were not clearly distinguished from one another. Prof. Debye showed how the total polarisation in an electric field is compounded of the natural polarisation inherent in the molecules themselves and of an induced polarisation, due to their electrical deformability; how the relative contributions of these two effects can be estimated by investigating the influence of temperature on dielectric constant; and how the magnitude of the natural dipole moment thus obtained can give valuable information on the degree and the nature of symmetry of the molecule. Examples were quoted from the work of Errera, Smyth and Williams.

IN the latter half of the lecture, Prof. Debye dealt with his pioneer investigations on X-ray interference patterns produced by isolated molecules, describing the technique, the application of the numerous necessary corrections to the experimental data, and the interpretation of the latter in terms of the interatomic distances in the molecule. Mention was made of the related electron ray method of Mark and Wierl. He illustrated his fascinating topic by reference to work on the chlorine substitution products of methane, and to the problem of free rotation of single bonds. The interest and enjoyment of his hearers were obvious. One may indeed be excused for thinking that very seldom are occasion and lecturer, theme and audience so completely attuned to one another as happened at this lecture. Prof. Debye had no difficulty in establishing Faraday as a pioneer of ideas in the fields both of the electrical properties of molecules and of the spatial arrangement of atoms within them. All felt that Sir William Bragg was right when he claimed that Prof. Debye and Faraday were akin in spirit; Prof. Donnan was equally right when he termed Prof. Debye the friend of the chemist, of the "hydrophobic organic chemist equally with the hydrophilic physical chemist".

\section{The Chemical Society}

Prof. G. G. Henderson, the retiring president of the Chemical Society, devoted his presidential address on March 30 to an examination of the present position and the future of the Society. Scientific societies, he said, must be ready to modify their policies in accordance with changing conditions. The work of the Chemical Societv in pursuing the 